\title{
Evaluation of waist-to-height ratio as a predictor of insulin resistance in non-diabetic obese individuals. A cross-sectional study
}

\author{
Giovana Jamar', Flávio Rossi de Almeida", Antonio Gagliardi"', Marianna Ribeiro Sobral"v, Chao Tsai Ping ', Evandro Sperandiov", \\ Marcelo Romiti"', Rodolfo Arantes 'II, Victor Zuniga Dourado VII
}

Universidade Federal de São Paulo (Unifesp), Santos, São Paulo (SP), Brazil

'MSc. Doctoral Student, Department of Biosciences, Universidade Federal de São Paulo (Unifesp), Santos, São Paulo (SP), Brazil.

"PT, MSc. Doctoral Student, Department of Human Movement Sciences, Universidade Federal de São Paulo (Unifesp), Santos, São Paulo (SP), Brazil. (D)orcid.org/0000-0003-4348-2241

"'MD, PhD. Researcher, Department of Cardiovascular Medicine, Angiocorpore Instituto de Medicina Cardiovascular, Santos, São Paulo (SP), Brazil.

"BM. Master's Student, Postgraduate Program on Food, Nutrition and Health, Federal University of São Paulo (Unifesp), Santos, São Paulo (SP), Brazil.

vphysiotherapist, Universidade Federal de São Paulo (Unifesp), Santos, São Paulo (SP), Brazil. viPT, PhD. Associate Professor, Laboratory of Epidemiology and Human Movement, Universidade Federal de São Paulo (Unifesp), Santos, São Paulo (SP), Brazil. (Dorcid.org/00000002-8580-458X

VIIPT, PhD. Associate Professor, Department of Human Movement Sciences, and Managing Professor, Laboratory of Epidemiology and Human Movement, Universidade Federal de São Paulo (Unifesp), Santos, São Paulo (SP), Brazil.

\section{KEY WORDS:}

Anthropometry.

Obesity.

Diabetes mellitus.

\begin{abstract}
BACKGROUND: Insulin resistance (IR) and progressive pancreatic $\beta$-cell dysfunction have been identified as the two fundamental features in the pathogenesis of obesity and non-insulin-dependent diabetes mellitus. We aimed to investigate correlations between anthropometric indices of obesity and IR in nondiabetic obese individuals, and the cutoff value from receiver operating characteristic (ROC) curve analysis. DESIGN AND SETTING: Cross-sectional study conducted in a private clinic.

METHODS: We included obese individuals (body mass index, BMI $\geq 30 \mathrm{~kg} / \mathrm{m}^{2}$ ) with no diabetes mellitus (fasting glucose levels $\leq 126 \mathrm{mg} / \mathrm{dl}$ ). The participants were evaluated for the presence of cardiovascular risk factors and through anthropometric measurements and biochemical tests. Furthermore, IR was assessed indirectly using the homeostatic model assessment (HOMA)-IR and HOMA- $\beta$ indexes. The area under the curve (AUC) of the variables was compared. The sensitivity, specificity and cutoff of each variable for diagnosing IR were calculated.

RESULTS: The most promising anthropometric parameters for indicating IR in non-diabetic obese individuals were waist-to-height ratio (WHtR), waist circumference (WC) and BMI. WHtR proved to be an independent predictor of IR, with risk increased by $0.53 \%$ in HOMA-IR, $5.3 \%$ in HOMA- $\beta$ and $1.14 \%$ in insulin. For HOMA-IR, WHtR had the highest AUC value (0.98), followed by WC (0.93) and BMI (0.81). For HOMA- $\beta$, WHtR also had the highest AUC value (0.83), followed by WC (0.75) and BMI (0.73). The optimal WHtR cutoff was 0.65 for HOMA-IR and 0.67 for HOMA- $\beta$.

CONCLUSION: Among anthropometric obesity indicators, WHtR was most closely associated with occurrences of $I R$ and predicted the onset of diabetes in obese individuals.
\end{abstract}

\section{INTRODUCTION}

Insulin resistance (IR) is considered to be one of the main risk factors for cardiovascular disease (CVD). It is associated with several metabolic abnormalities such as impaired glucose tolerance, noninsulin-dependent diabetes mellitus (NIDDM), hypertension and dyslipidemia. ${ }^{1,2}$ Maintenance of normal blood glucose comes mainly from the ability of $\beta$-pancreatic cells to secrete insulin and the sensitivity of the target tissues to respond to normal levels of insulin in the bloodstream. ${ }^{3}$

The homeostasis model assessment (HOMA) is a widely validated clinical and epidemiological tool for estimating IR and $\beta$-cell function. It is derived from a mathematical assessment of the balance between hepatic glucose output and insulin secretion from fasting levels of glucose and insulin. ${ }^{4}$ HOMA-IR and HOMA- $\beta$ have been adopted as an alternative to the gold standard method, i.e. the hyperinsulinemic-euglycemic clamp technique. Although use of HOMA indices requires an invasive access, ${ }^{5}$ it is inexpensive and easy to apply. ${ }^{6}$

One aspect of research on obesity that is currently attracting attention is the distribution of fat in the body. Diabetes, atherosclerosis and sudden cardiac death occur quite frequently among obese people, but when obesity is centralized in the abdominal region, the negative repercussions (both metabolic and cardiovascular) are more significant. ${ }^{7}$ Several studies have evaluated the correlation between IR and anthropometric indices of obesity such as body mass index (BMI), waist circumference (WC), neck circumference (NC) and hip circumference (HP). They have demonstrated that the distribution of visceral fat causes significant damage to the insulin-signaling pathway due to secretion of adipokines, e.g. C-reactive protein (CRP), ${ }^{2,8,9}$ thus leading to increased cardiometabolic risk. ${ }^{10}$ Therefore, obesity is the most prominent predictor of IR and diabetes. ${ }^{11}$ 
Anthropometry is considered to be a non-invasive tool for early diagnosis of the onset of NIDDM. In addition, it provides an alternative evaluation of IR at lower cost that is accessible for application in epidemiological studies and primary care within health services. ${ }^{8}$ However, there is no consensus regarding which anthropometric measurement is most indicative of IR in non-diabetic obese subjects, or regarding the cutoff values.

\section{OBJECTIVE}

We aimed to investigate the correlations between anthropometric indices of obesity and IR in non-diabetic obese individuals, and to identify the best cutoff values of these indices for predicting IR, through using receiver operating characteristic (ROC) curve analyses.

\section{METHODS}

\section{Participants}

This study used a cross-sectional design. The participants were selected as a convenience sample of consecutive patients admitted between 2013 and 2015, when they presented the following inclusion criteria: $\mathrm{BMI} \geq 30 \mathrm{~kg} / \mathrm{m}^{2}$ and no diabetes mellitus (DM) (reported or fasting blood glucose $\leq 126 \mathrm{mg} / \mathrm{dl}$ ). ${ }^{12,13}$ We enrolled 136 obese individuals, comprising 72 men and 64 women, at the Obesity Clinic of the Angiocorpore Institute of Cardiovascular Medicine, located in the city of Santos, São Paulo, Brazil. They had been referred for the examinations because of a variety of medical indications. This study formed part of a larger study assessing the determinants of exercise intolerance among obese individuals. All the participants agreed to participate, and none of them presented abnormalities during the examinations that would exclude them.

The Ethics Committee for Research on Human Beings of the Federal University of São Paulo (Universidade Federal de São Paulo, UNIFESP) approved this study under the number 1.079.239. Furthermore, an informed consent statement was signed by all of these volunteers.

\section{Anthropometric obesity indices}

Body weight and height were measured by using a weighing scale with stadiometer that measured to precisions of the nearest $0.1 \mathrm{~kg}$ and $1 \mathrm{~cm}$ (Toledo, São Paulo, Brazil). The individuals were weighed without shoes. The neck (NC), waist (WC) and hip (HC) circumferences were measured in $\mathrm{cm}$ using an inelastic tape (Sanny) with precision of $1 \mathrm{~mm}$. We measured $\mathrm{NC}$ at the midpoint of the neck; WC at the midpoint between the last rib and the iliac crest; and $\mathrm{HC}$ at the point of greatest gluteal protuberance. ${ }^{14,15}$ From these anthropometric measurements, we obtained indices relating to cardiometabolic health: waist-to-hip ratio (WHR), waist/height ratio (WHtR), body mass index $\left(\mathrm{BMI}=\right.$ weight $_{\mathrm{kg}} /$ height $\left._{\mathrm{m}^{2}}\right)$ and body shape index $\left(\mathrm{BSI}=\mathrm{WC} / \mathrm{BMI}^{2 / 3} \mathrm{x}\right.$ height $\left.{ }^{1 / 2}\right) .^{16}$

\section{Blood test}

Blood samples were collected for laboratory-based biochemical measurements after the participants had fasted for 12 hours. We quantified C-reactive protein (CRP, ng/ml), total cholesterol (mg/dl), HDL cholesterol (mg/dl), LDL cholesterol (mg/dl), insulin (IU/dl) and glucose (mg/dl). Glucose values were converted from $\mathrm{mg} / \mathrm{dl}$ to $\mathrm{mmol} / \mathrm{l}$ using the conversion factor $0.555 .{ }^{13}$

\section{IR assessment}

We used the homeostasis model assessments HOMA-IR and HOMA- $\beta$ to indirectly determine IR, based on glucose and insulin values proposed by Matthews et al. ${ }^{3}$ IR was defined as situations with HOMA-IR $\geq 2.7,{ }^{17-21}$ and dysfunction of $\beta$-cells as situations with HOMA- $\beta>175 .^{4,22}$

\section{Cardiovascular risk assessment}

We assessed self-reported cardiovascular risk factors in accordance with the recommendations of the American College of Sports Medicine (ACSM). The participants were asked to report any previous diagnosis of the main cardiovascular risk factors such as arterial hypertension, dyslipidemia and diabetes, along with their age, situation of physical inactivity and smoking status. We considered that the participants were physically inactive if they reported doing less than 150 minutes per week of moderate-to-vigorous physical activity. ${ }^{23}$

\section{Statistical analysis}

We assessed correlations between anthropometric indices and HOMA-IR values, HOMA- $\beta$ values and insulin concentration using Pearson correlation coefficients. Three models of stepwise multiple linear regressions were then fitted, with HOMA-IR, HOMA- $\beta$ and insulin as the main outcomes. The main predictors that we chose were the anthropometric indices that significantly correlated with outcomes after univariate analysis. We checked for multicollinearity in the models by means of variation inflation factor (VIF) values $<4$. The models were also adjusted for age, sex and cardiovascular risk factors.

We fitted ROC curves to assess the best cutoff points for anthropometric measurements for predicting clinically high values of HOMA-IR and HOMA- $\beta$ as surrogate measurements for IR. The areas under the ROC curves (AUC) and the $95 \%$ confidence intervals ( $95 \% \mathrm{CI}$ ) were used to compare the diagnostic value of various obesity indices. We considered that values above 0.80 were excellent. The main anthropometric indices selected after multiple linear regression were used to obtain the optimal cutoff 
point for diagnosing IR. We calculated the sensitivity, specificity, positive and negative likelihood ratios and Youden index in relation to these values.

All tests were evaluated at a two-tailed alpha level of 0.05 . All statistical analyses were performed using the Statistical Package for the Social Sciences (SPSS), version 23 (SPSS Inc., Chicago, USA), and the MedCalc package, version 17 (MedCalc Software bvba, Belgium).

\section{RESULTS}

\section{Baseline characteristics of the participants}

The men and women involved in the present study were on average middle-aged. We found significantly higher values for weight, height, WC, WHR, NC and BSI among the men, while HC and BMI were significantly higher among the women. The participants were mostly physically inactive. We observed a greater proportion of dyslipidemia among the men and higher fasting glucose among the women (Table 1).

When stratified according to nutritional status, we found progressively impaired values for fasting insulin, HOMA-IR and HOMA- $\beta$ with increasing severity of obesity, while CRP presented

Table 1. General characteristics of the study sample according to sex. Mean \pm standard deviation (SD).

\begin{tabular}{|c|c|c|c|}
\hline & $\begin{array}{l}\text { Females } \\
(n=64)\end{array}$ & $\begin{array}{c}\text { Males } \\
(n=72)\end{array}$ & $\mathbf{P}$ \\
\hline Age (years) & $37 \pm 10$ & $34 \pm 8$ & 0.054 \\
\hline Weight (kg) & $106 \pm 11$ & $120 \pm 17^{*}$ & 0.000 \\
\hline Height (m) & $1.62 \pm 0.05$ & $1.75 \pm 0.08^{*}$ & 0.000 \\
\hline Body mass index $\left(\mathrm{kg} / \mathrm{m}^{2}\right)$ & $40.5 \pm 4.8$ & $38.8 \pm 4.5^{*}$ & 0.034 \\
\hline Waist circumference $(\mathrm{cm})$ & $111 \pm 8$ & $118 \pm 11^{*}$ & 0.000 \\
\hline Hip circumference $(\mathrm{cm})$ & $129 \pm 9$ & $120 \pm 9 *$ & 0.000 \\
\hline Waist-to-hip ratio & $0.86 \pm 0.07$ & $0.98 \pm 0.07^{*}$ & 0.000 \\
\hline Neck circumference (cm) & $38 \pm 3$ & $44 \pm 3^{*}$ & 0.000 \\
\hline Body shape index & $7.4 \pm 0.4$ & $7.8 \pm 0.45^{*}$ & 0.000 \\
\hline Waist-to-height ratio & $0.69 \pm 0.06$ & $0.68 \pm 0.06$ & 0.333 \\
\hline \multicolumn{4}{|c|}{ Cardiovascular risk assessment and biochemical analysis } \\
\hline Arterial hypertension & $20(23.8)$ & $15(20.0)$ & 0.592 \\
\hline Dyslipidemia & $10(11.9)$ & $21(28.0)^{*}$ & 0.020 \\
\hline Physical inactivity & $63(75.0)$ & $55(73.3)$ & 0.821 \\
\hline Current smoking & $13(15.4)$ & $14(18.6)$ & 0.620 \\
\hline $\mathrm{HDL}(\mathrm{mg} / \mathrm{dl})$ & $50 \pm 15$ & $50 \pm 13$ & 1.000 \\
\hline $\mathrm{LDL}(\mathrm{mg} / \mathrm{dl})$ & $115 \pm 32$ & $121 \pm 34$ & 0.292 \\
\hline Total cholesterol (mg/dl) & $196 \pm 38$ & $201 \pm 32$ & 0.406 \\
\hline Fasting glucose (mg/dl) & $93 \pm 10$ & $89 \pm 11^{*}$ & 0.028 \\
\hline Fasting insulin (IU/ml) & $19 \pm 9$ & $17 \pm 10$ & 0.224 \\
\hline HOMA-IR & $4.72 \pm 2.58$ & $3.81 \pm 2.50$ & 0.058 \\
\hline НОМА- $\beta$ & $71.6 \pm 35.8$ & $64.9 \pm 42.9$ & 0.327 \\
\hline
\end{tabular}

$\mathrm{HDL}=$ high-density lipoprotein; $\mathrm{LDL}=$ low-density lipoprotein; $\mathrm{HOMA}-\mathrm{IR}=$ homeostasis model assessment - insulin resistance; HOMA- $\beta=$ homeostasis model assessment - beta-cell function

${ }^{*} \mathrm{P}<0.05=$ females versus males. a significant difference only at obesity level I and total cholesterol at obesity level III (Table 2).

\section{Correlation and multiple regression analysis}

We found strong correlations of WHtR, WC and BMI with HOMA-IR, HOMA- $\beta$ and fasting insulin. On the other hand, WHR, NC and BSI showed weak correlations (Table 3). A stepwise multiple linear regression analysis was performed with HOMA-IR, HOMA- $\beta$ and insulin as dependent variables. After adjustment for age, sex and obesity indices, WHtR proved to be an independent predictor of IR in this study (Table 4).

\section{ROC curves}

The abilities of WHtR, WC and BMI to detect IR were compared using ROC curves. For HOMA-IR, we found an AUC of 0.98 for WHtR, 0.83 for WC and 0.81 for BMI, such that the AUC was significantly greater for WHtR than for WC (difference between areas $=0.150 ; \mathrm{P}<0.001$ ) and BMI (difference between areas $=0.171 ; \mathrm{P}<0.001)$. We found that there was no significant difference in AUC between WC and BMI (difference between areas $=0.021 ; \mathrm{P}=0.629$ ) (Figure 1). Regarding HOMA- $\beta$, the AUC of 0.83 for WHtR

Table 2. Description of anthropometric measurements and biochemical analysis between obesity levels. Mean \pm standard deviation (SD).

\begin{tabular}{|c|c|c|c|}
\hline & $\begin{array}{l}\text { Obesity I } \\
(n=20)\end{array}$ & $\begin{array}{l}\text { Obesity II } \\
(n=63)\end{array}$ & $\begin{array}{l}\text { Obesity III } \\
\quad(n=53)\end{array}$ \\
\hline \multicolumn{4}{|l|}{ Anthropometric parameters } \\
\hline Weight (kg) & $101 \pm 10.5$ & $108 \pm 12.0$ & $124 \pm 15.6^{d}$ \\
\hline Height (cm) & $172 \pm 0.0$ & $169 \pm 0.0$ & $166 \pm 0.0^{b}$ \\
\hline Waist circumference (cm) & $107 \pm 6$ & $113 \pm 8$ & $121 \pm 10^{d}$ \\
\hline Hip circumference $(\mathrm{cm})$ & $115 \pm 4.6$ & $121 \pm 7.2$ & $133 \pm 8.8^{\text {ad }}$ \\
\hline Neck circumference (cm) & $40 \pm 3.1$ & $41 \pm 4.2$ & $41 \pm 4.8$ \\
\hline Waist-to-hip ratio & $0.93 \pm 0.07$ & $0.93 \pm 0.89$ & $0.90 \pm 0.10$ \\
\hline Waist-to-height ratio & $0.62 \pm 0.03$ & $0.67 \pm 0.05$ & $0.73 \pm 0.06^{\mathrm{ac}}$ \\
\hline Body mass index $\left(\mathrm{kg} / \mathrm{m}^{2}\right)$ & $33.8 \pm 0.8$ & $37.6 \pm 1.3$ & $44.9 \pm 3.6^{\mathrm{ad}}$ \\
\hline Body shape index & $7.8 \pm 0.4$ & $7.7 \pm 0.5$ & $7.4 \pm 0.5^{\mathrm{bc}}$ \\
\hline \multicolumn{4}{|l|}{ Biochemical analysis } \\
\hline C-reactive protein (ng/ml) & $2.15 \pm 2.86$ & $0.93 \pm 1.15$ & $0.92 \pm 0.98^{e}$ \\
\hline Total cholesterol (mg/dl) & $198 \pm 35$ & $191 \pm 32$ & $208 \pm 38^{c}$ \\
\hline $\mathrm{HDL}(\mathrm{mg} / \mathrm{dl})$ & $53 \pm 16$ & $48 \pm 13$ & $51 \pm 14$ \\
\hline $\mathrm{LDL}(\mathrm{mg} / \mathrm{dl})$ & $124 \pm 25$ & $116 \pm 27$ & $119 \pm 43$ \\
\hline Fasting glucose (mg/dl) & $88 \pm 9$ & $91 \pm 11$ & $93 \pm 11$ \\
\hline Fasting insulin (IU/ml) & $9.6 \pm 4.0$ & $15.0 \pm 6.2$ & $25.6 \pm 11.6^{\mathrm{d}}$ \\
\hline HOMA-IR & $2.1 \pm 1.0$ & $3.4 \pm 1.6$ & $6.0 \pm 2.8^{d}$ \\
\hline HOMA- $\beta$ & $35.5 \pm 15$ & $55.7 \pm 23$ & $95.3 \pm 45^{d}$ \\
\hline
\end{tabular}

$\mathrm{HDL}$ = high-density lipoprotein; $\mathrm{LDL}=$ low-density lipoprotein; $\mathrm{HOMA}$ $\mathbb{R}=$ homeostasis model assessment - insulin resistance; $\mathrm{HOMA}-\beta=$ homeostasis model assessment - beta-cell function.

$\mathrm{a}=$ obesity I versus obesity II, $\mathrm{P}<0.05$. b: obesity I versus obesity III, $\mathrm{P}<0.05$. $c=$ obesity $\|$ versus obesity III, $P<0.05 . d=$ obesity I and obesity $\|$ versus obesity III, P $<0.05$. e: obesity II and obesity III versus obesity I, $\mathrm{P}<0.05$. 
was significantly greater than the AUC for WC $(0.75$, difference between areas $=0.082 ; \mathrm{P}=0.013)$ and $\mathrm{BMI}(0.73$, difference between areas $=0.099 ; \mathrm{P}=0.009)$, with no significant difference between WC and BMI (difference between areas $=0.017 ; \mathrm{P}=0.727$ ) (Figure 2 ). The best cutoff points for HOMA-IR were $0.65,113 \mathrm{~cm}$ and $38.76 \mathrm{~kg} / \mathrm{m}^{2}$ and for HOMA- $\beta$ were $0.67,112 \mathrm{~cm}$ and $37.61 \mathrm{~kg} / \mathrm{m}^{2}$, respectively for WHtR, WC and BMI (Table 5).

\section{DISCUSSION}

In the present study, we observed that not all the anthropometric parameters studied were significantly associated with HOMA-IR and HOMA- $\beta$. The most promising anthropometric parameters for indicating IR in non-diabetic obese adults were WHtR, WC and BMI. Our results suggest that there are advantages to using WHtR. In our analysis, we observed that the risk of IR was raised by $0.53 \%$ in HOMA-IR, $5.3 \%$ in HOMA- $\beta$ and $1.14 \%$ in insulin for each additional $1 \%$ increase in WHtR $(=0.01)$. Thus, WHtR was a predictor for the degree of IR and predisposition towards diabetes in our sample of obese individuals. Recently, Vikam et al. ${ }^{10}$ observed increased odds ratios for hyperinsulinemia and metabolic syndrome among individuals with WHtR $>0.5$.

Use of WHtR for detecting abdominal obesity and its associated risks to health was first proposed in the 1990s. ${ }^{24}$ The growing

Table 3. Matrix of correlations between obesity indices and values for homeostasis model assessment - insulin resistance (HOMA-IR) and for HOMA - beta-cell function (HOMA- $\beta$ ) in the study sample

\begin{tabular}{|c|c|c|c|c|c|c|c|c|c|c|}
\hline & & HOMA-IR & НОМА- $\beta$ & Insulin (IU/ml) & WHtR & WC $(\mathrm{cm})$ & BMI $\left(\mathrm{kg} / \mathrm{m}^{2}\right)$ & WHR & $\mathrm{NC}(\mathrm{cm})$ & BSI \\
\hline \multirow{3}{*}{ HOMA-IR } & $r$ & 1 & $0.853^{*}$ & $0.920^{*}$ & $0.846^{*}$ & $0.648^{*}$ & $0.669^{*}$ & 0.164 & 0.114 & $0.197^{\dagger}$ \\
\hline & $\mathrm{p}$ & & 0.00 & 0.00 & 0.00 & 0.00 & 0.00 & 0.061 & 0.197 & 0.024 \\
\hline & $\mathrm{p}^{\dagger}$ & & 0.086 & 0.334 & 0.242 & 0.974 & 0.399 & 0.377 & 0.377 & 0.019 \\
\hline \multirow{3}{*}{ НOMA- $\beta$} & $r$ & $0.753^{*}$ & 1 & $0.944^{*}$ & $0.905^{*}$ & $0.753^{*}$ & $0.690^{*}$ & $0.277^{*}$ & $0.192^{+}$ & $0.283^{*}$ \\
\hline & $p$ & 0.00 & & 0.00 & 0.00 & 0.00 & 0.00 & 0.001 & 0.029 & 0.001 \\
\hline & $\mathrm{p}^{\dagger}$ & 0.086 & & 0.097 & 0.163 & 0.764 & 0.154 & 0.635 & 0.023 & 0.078 \\
\hline \multirow{3}{*}{ Insulin } & $r$ & $0.920^{*}$ & $0.944^{*}$ & 1 & $0.935^{*}$ & $0.754^{*}$ & $0.720^{*}$ & $0.243^{*}$ & 0.163 & $0.267^{*}$ \\
\hline & $\mathrm{p}$ & 0.00 & 0.00 & & 0.00 & 0.00 & 0.00 & 0.005 & 0.064 & 0.002 \\
\hline & $\mathrm{p}^{\dagger}$ & 0.334 & 0.097 & & 0.186 & 0.239 & 0.644 & 0.512 & 0.096 & 0.086 \\
\hline \multirow{3}{*}{ WHtR } & $r$ & $0.846^{*}$ & $0.905^{*}$ & $0.935^{*}$ & 1 & $0.876^{*}$ & $0.811^{*}$ & $0.452^{*}$ & $0.314^{*}$ & $0.448^{*}$ \\
\hline & $p$ & 0.00 & 0.00 & 0.00 & & 0.00 & 0.00 & 0.00 & 0.00 & 0.00 \\
\hline & $\mathrm{p}^{\dagger}$ & 0.242 & 0.163 & 0.186 & & 0.533 & 0.155 & 0.088 & 0.274 & 0.085 \\
\hline \multirow{3}{*}{$\mathrm{WC}(\mathrm{cm})$} & $r$ & $0.648^{*}$ & $0.753^{*}$ & $0.754^{*}$ & $0.876^{*}$ & 1 & $0.688^{*}$ & $0.658^{*}$ & $0.604^{*}$ & $0.608^{*}$ \\
\hline & $p$ & 0.00 & 0.00 & 0.00 & 0.00 & & 0.00 & 0.00 & 0.00 & 0.00 \\
\hline & $\mathrm{p}^{\dagger}$ & 0.974 & 0.764 & 0.239 & 0.533 & & 0.256 & & 0.422 & 0.168 \\
\hline \multirow{3}{*}{$\begin{array}{l}\text { BMI } \\
\left(\mathrm{kg} / \mathrm{m}^{2}\right)\end{array}$} & $r$ & $0.669^{*}$ & $0.690 *$ & $0.720^{*}$ & $0.811^{*}$ & $0.688^{*}$ & 1 & 0.051 & $0.222^{*}$ & -0.106 \\
\hline & $p$ & 0.00 & 0.00 & 0.00 & 0.00 & 0.00 & & 0.525 & 0.005 & 0.184 \\
\hline & $\mathrm{p}^{\dagger}$ & 0.399 & 0.154 & 0.644 & 0.155 & 0.256 & & 0.067 & 0.278 & 0.205 \\
\hline \multirow{3}{*}{ WHR } & $r$ & 0.164 & $0.277^{*}$ & $0.243^{*}$ & $0.452^{*}$ & $0.658^{*}$ & 0.051 & 1 & $0609^{*}$ & $0.832^{*}$ \\
\hline & $r$ & 0.061 & 0.001 & 0.005 & 0.00 & 0.00 & 0.525 & & 0.00 & 0.00 \\
\hline & $\mathrm{p}^{\dagger}$ & 0.377 & 0.635 & 0.512 & 0.088 & 0.533 & 0.067 & & 0.533 & 0.090 \\
\hline \multirow{3}{*}{$\mathrm{NC}(\mathrm{cm})$} & $r$ & 0.114 & $0.192^{\dagger}$ & 0.163 & $0.314^{*}$ & $0.604^{*}$ & $0.222^{*}$ & $0.609 *$ & 1 & $0.444^{*}$ \\
\hline & $p$ & 0.197 & 0.029 & 0.064 & 0.00 & 0.00 & 0.005 & 0.00 & & 0.00 \\
\hline & $\mathrm{p}^{\dagger}$ & 0.377 & 0.023 & 0.064 & 0.274 & 0.422 & 0.278 & 0.533 & & 0.067 \\
\hline \multirow{3}{*}{ BSI } & $r$ & $0.197^{\dagger}$ & $0.283^{*}$ & $0.267^{*}$ & $0.448^{*}$ & $0.608 *$ & -0.106 & $0.832^{*}$ & $0.444^{*}$ & 1 \\
\hline & $p$ & 0.024 & 0.001 & 0.002 & 0.00 & 0.00 & 0.184 & 0.00 & 0.00 & \\
\hline & $\mathrm{p}^{\dagger}$ & 0.019 & 0.078 & 0.086 & 0.085 & 0.168 & 0.205 & 0.090 & 0.067 & \\
\hline
\end{tabular}

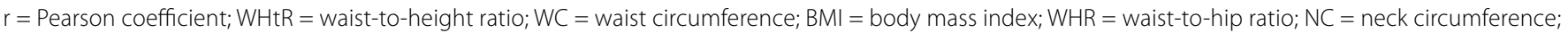
$\mathrm{BSI}=$ body shape index. *Significant correlations for all subjects; †Significant correlations for females versus males.

Table 4. Multiple regression analysis on obesity indices that predict insulin resistance

\begin{tabular}{|c|c|c|c|c|c|}
\hline Dependent variable & Predictors & $\beta$ & $95 \% \mathrm{Cl}$ & $\mathbf{R}^{2}$ & $\mathbf{P}$ \\
\hline HOMA-IR & waist-to-height ratio & $0.53^{*}$ & $0.47-0.59$ & 0.71 & $<0.01$ \\
\hline HOMA- $\beta$ & waist-to-height ratio & $5.30^{*}$ & $4.93-5.67$ & 0.82 & $<0.01$ \\
\hline Insulin (IU/ml) & waist-to-height ratio & $1.14^{*}$ & $1.04-1.25$ & 0.73 & $<0.01$ \\
\hline
\end{tabular}

$\mathrm{WHtR}=$ waist-to-height ratio; HOMA-IR = homeostasis model assessment - insulin resistance; HOMA- $\beta=$ homeostasis model assessment - beta-cell function. *WHtR values are expressed in percentage. Models adjusted for age, sex, weight, waist circumference, neck circumference, body mass index, waist-hip ratio, waist-to-height ratio and body shape index. 
body of literature showed that this abdominal obesity indicator could predict the cardiometabolic risk even better than BMI and WC. ${ }^{25}$ A recent meta-analysis on studies evaluating different indices of adiposity showed that WHtR was a better predictor for hyperinsulinemia, diabetes, arterial hypertension, dyslipidemia, metabolic syndrome and other cardiovascular health problems than were BMI or WC, in both men and women. ${ }^{26}$ In addition, our AUC values for this anthropometric obesity indicator were higher than in previous prediction studies with WHtR, ${ }^{11,27,28}$ thus emphasizing the accuracy of AUC measurements for identifying IR in obese populations. According to Behboudi-Gandevani et al., ${ }^{11}$ WHtR may be proposed as a sensitive, inexpensive, noninvasive, simple-to-assess and easy-tocalculate tool for screening for IR.

Taking into account that ethnicity and gender may influence body composition, studies on Brazilian and Indian overweight women also showed that the WHtR was the most important predictive measurement for IR and diabetes. ${ }^{27,29}$ However, studies on men of different ethnicity indicated that BMI was the best predictor for IR. ${ }^{28,30,31}$ It should be noted that BMI is characterized as an indicator of general adiposity because of its inability to assess the distribution of body fat, thus presenting a weaker relationship with visceral fat. ${ }^{27}$ In a recent meta-analysis, Savva et al. ${ }^{32}$ compared the association of BMI and WHtR with the cardiometabolic risk factor of diabetes in Asian and non-Asian populations. The data from cross-sectional studies indicated that WHtR is superior to BMI for detecting diabetes in both Asian and non-Asian populations. There are still few studies of this design on Brazilian populations, especially in relation to obese individuals. ${ }^{32}$

The risk of developing obesity-related comorbidities is proportional to the degree of obesity and, more specifically, the accumulation of visceral fat. ${ }^{33}$ However, the presence of metabolic disorders varies considerably among obese individuals, ${ }^{34}$ since it is known that there is one subgroup of obese individuals that seems to be protected against or is more resistant to developing cardiometabolic complications. ${ }^{35}$ Nevertheless, regarding phenotypes for metabolic status and diabetes, healthy obese and metabolically unhealthy normal-weight individuals appear to have an equivalent risk. ${ }^{36}$

In the general population, a WHtR cutoff $<0.5$ is recommended, which can be presented as a simple public health message that individuals should seek to maintain their WC as less than half of their height. We showed that the higher this ratio is, the higher the risk of indirect IR is, and we proposed a cutoff $>0.65$ to identify IR in non-diabetic obese individuals. This indicates that there is a need for a specific evaluation on this population, for early detection of IR that could ultimately reduce the incidence or severity of diabetes and cardiovascular diseases.

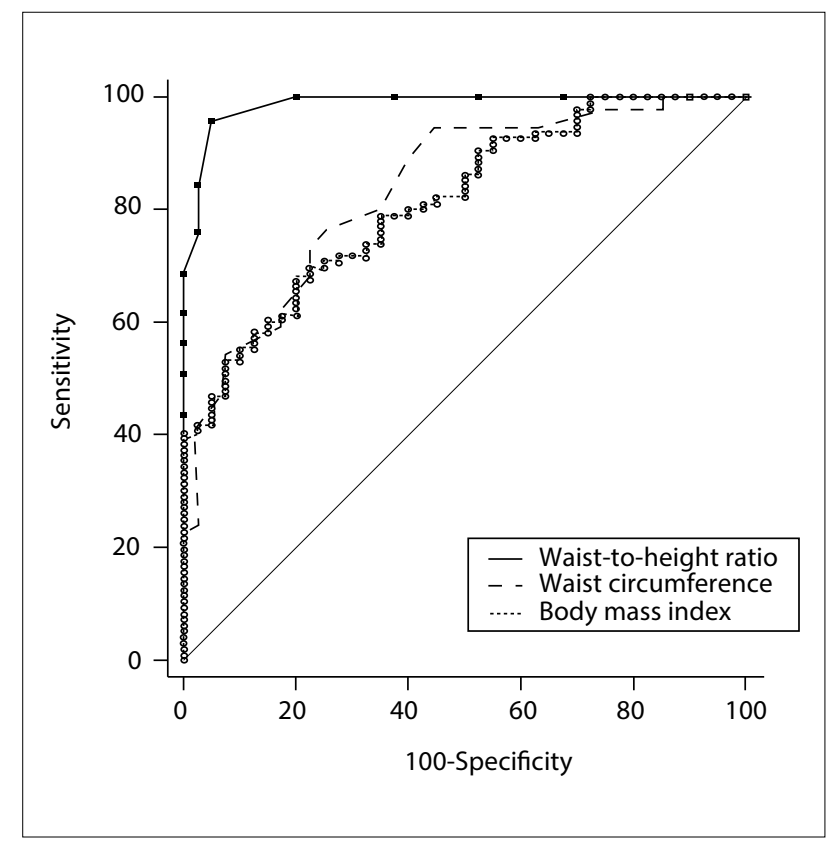

Figure 1. Receiver operating characteristic (ROC) curve for anthropometric parameters that predict insulin resistance according to the homeostatic model assessment-insulin resistance (HOMA-IR). The areas under the ROC curves and the $95 \%$ confidence intervals $(95 \% \mathrm{Cl})$ were $0.98(0.95-0.99)$ for waist-toheight ratio (WHtR); 0.93 (0.76-0.89) for waist circumference (WC); and 0.81 (0.74-0.87) for body mass index (BMI).

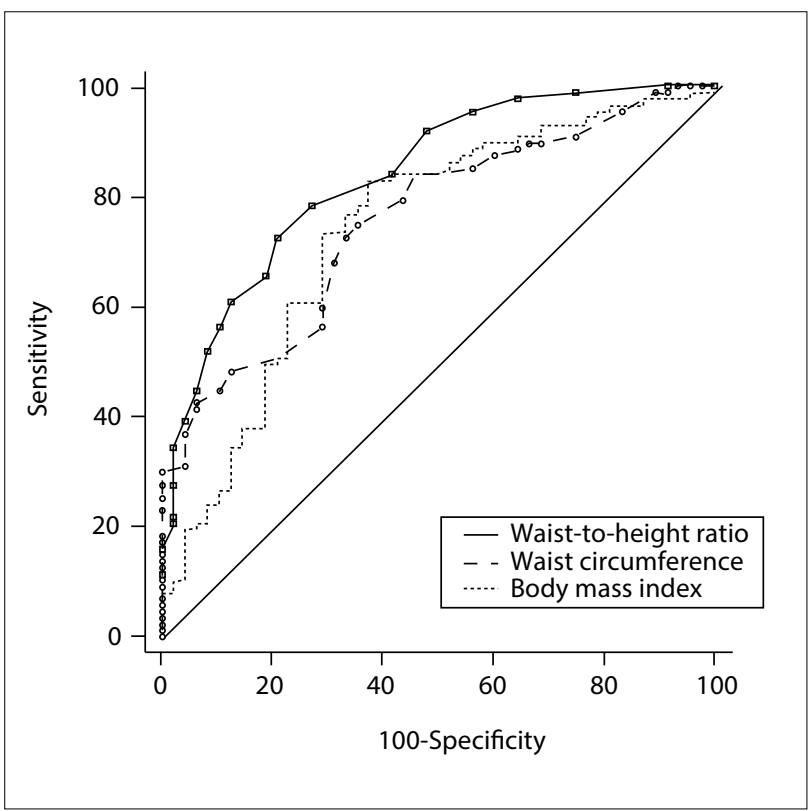

Figure 2. Receiver operating characteristic (ROC) curve for anthropometric parameters that predict insulin resistance according to the homeostatic model assessment (HOMA)- $\beta$. The areas under the ROC curves and the $95 \%$ confidence intervals $(95 \% \mathrm{Cl})$ were $0.83(0.76-0.89)$ for waist-to-height ratio (WHtR); 0.75 (0.67-0.82) for waist circumference (WC); and $0.73(0.65-0.81)$ for body mass index (BMI). 
Table 5. Optimal cutoff point values and their related sensitivity, specificity, positive and negative likelihood ratios and Youden index for obesity indices, regarding discrimination of insulin resistance

\begin{tabular}{|c|c|c|c|c|c|c|c|}
\hline Outcome & Variable & $\begin{array}{l}\text { Cutoff } \\
\text { point }\end{array}$ & Sensitivity $(95 \% \mathrm{Cl})$ & Specificity $(95 \% \mathrm{Cl})$ & +LR $(95 \% \mathrm{Cl})$ & -LR $(95 \% \mathrm{Cl})$ & $\begin{array}{c}\text { Youden } \\
\text { index }\end{array}$ \\
\hline \multirow{3}{*}{ HOMA-IR } & Waist-to-height ratio & $>0.65$ & $95.83(89.7-98.9)$ & $95.00(83.1-99.4)$ & $19.17(5.0-74.0)$ & $0.04(0.02-0.1)$ & 0.90 \\
\hline & Waist circumference (cm) & $>113.00$ & $73.96(64.0-82.4)$ & $77.50(61.5-89.2)$ & $3.29(1.8-5.9)$ & $0.34(0.2-0.5)$ & 0.51 \\
\hline & $\begin{array}{c}\text { Body mass } \\
\text { index }\left(\mathrm{kg} / \mathrm{m}^{2}\right)\end{array}$ & $>38.76$ & $67.71(57.4-76.9)$ & $80.00(64.4-90.9)$ & $3.39(1.8-6.4)$ & $0.40(0.3-0.6)$ & 0.47 \\
\hline \multirow{3}{*}{ HOMA- $\beta$} & Waist-to-height ratio & $>0.67$ & $72.41(61.8-81.5)$ & $79.17(65.0-89.5)$ & $3.48(2.0-6.1)$ & $0.35(0.2-0.5)$ & 0.51 \\
\hline & Waist circumference (cm) & $>112.0$ & $74.71(64.3-83.4)$ & $64.58(49.5-77.8)$ & $2.11(1.4-3.2)$ & $0.39(0.3-0.6)$ & 0.39 \\
\hline & $\begin{array}{c}\text { Body mass } \\
\text { index }\left(\mathrm{kg} / \mathrm{m}^{2}\right)\end{array}$ & $>37.61$ & $82.76(73.2-90.0)$ & $62.50(47.4-76.0)$ & $2.21(1.5-3.2)$ & $0.28(0.2-0.5)$ & 0.45 \\
\hline
\end{tabular}

HOMA-IR = homeostasis model assessment - insulin resistance; HOMA- $\beta=$ homeostasis model assessment - beta-cell function; $+\mathrm{LR}=$ positive likelihood ratio; $-L R=$ negative likelihood ratio.

In summary, we found that WHtR may be useful in clinical practice due to its advantageous simplicity. Also, it is easy to calculate, does not require any special equipment other than an inelastic tape, and only requires some rater training.

The present study has limitations that should be considered. Our sample was not enough to extract the cutoff points according to sex. Since not all obese individuals have metabolic alterations, our strategy was to ascertain which anthropometric measurements were better correlated with IR, and whether non-diabetic obese individuals would present a cutoff point different from general population for predicting the onset of diabetes, thereby suggesting different reference values for a more accurate assessment in this specific group. Perhaps inclusion of a eutrophic group would have contributed towards reinforcing our important findings. Future research should aim to screen Brazilian obese populations, in order to provide support for our remarks.

\section{CONCLUSION}

We can conclude that the WHtR is a strong predictor of IR, as assessed using HOMA, among non-diabetic obese adults. Our results suggest that WHtR can form a simple and powerful tool for screening for IR among these patients, since we found convincing AUC and sensitivity and specificity values for this index in detecting clinically high values of HOMA-IR and HOMA- $\beta$.

\section{REFERENCES}

1. Goldfine AB, Conlin PR, Halperin F, et al. A randomised trial of salsalate for insulin resistance and cardiovascular risk factors in persons with abnormal glucose tolerance. Diabetologia. 2013;56(4):714-23.

2. Carneiro IBP, Sampaio HAC, Carioca AAF, Pinto FJM, Damasceno NRT. Antigos e novos indicadores antropométricos como preditores de resistência à insulina em adolescentes [Old and new anthropometric indices as insulin resistance predictors in adolescentes]. Arq Bras Endocrinol Metabol. 2014;58(8):838-43.
3. Matthews DR. Insulin resistance and beta-cell function--a clinical perspective. Diabetes Obes Metab. 2001;3 Suppl 1:S28-33.

4. Song $Y$, Manson JE, Tinker $L$, et al. Insulin sensitivity and insulin secretion determined by homeostasis model assessment and risk of diabetes in a multiethnic cohort of women: the Women's Health Initiative Observational Study. Diabetes Care. 2007;30(7):1747-52.

5. Wallace TM, Levy JC, Matthews DR. Use and abuse of HOMA modeling. Diabetes Care. 2004;27(6):1487-95.

6. Matthews DR, Hosker JP, Rudenski AS, et al. Homeostasis model assessment: insulin resistance and beta-cell function from fasting plasma glucose and insulin concentrations in man. Diabetologia. 1985;28(7):412-9.

7. de Koning L, Merchant AT, Pogue J, Anand SS. Waist circumference and waist-to-hip ratio as predictors of cardiovascular events: meta-regression analysis of prospective studies. Eur Heart J. 2007;28(7):850-6.

8. Vázquez-Vela ME, Torres N, Tovar AR. White adipose tissue as endocrine organ and its role in obesity. Arch Med Res. 2008;39(8):715-28.

9. Lim SM, Choi DP, Rhee Y, Kim HC. Association between Obesity Indices and Insulin Resistance among Healthy Korean Adolescents: The JS High School Study. PLoS One. 2015;10(5):e0125238.

10. Vikram NK, Latifi AN, Misra A, et al. Waist-to-Height Ratio Compared to Standard Obesity Measures as Predictor of Cardiometabolic Risk Factors in Asian Indians in North India. Metab Syndr Relat Disord. 2016;14(10):492-499.

11. Behboudi-Gandevani S, Ramezani Tehrani F, Cheraghi L, Azizi F. Could"a body shape index" and "waist to height ratio" predict insulin resistance and metabolic syndrome in polycystic ovary syndrome? Eur J Obstet Gynecol Reprod Biol. 2016;205:110-4.

12. Vasques $A C$, Geloneze B, Rosado L, et al. Indicadores antropométricos de resistência à insulina [Anthropometric indicators of insulin resistance]. Arq Bras Cardiol. 2010;95(1):e14-e23.

13. American Diabetes Association. Diagnosis and classification of diabetes mellitus. Diabetes Care. 2014;37 Suppl 1:S81-90.

14. Lohman TG, Roche AF, Martorell R. Anthropometric standardization reference manual. Champaign: Human Kinetics Books; 1988.

15. Ben-NounL,SoharE, Laor A. Neck circumference as a simple screening measure for identifying overweight and obese patients. Obes Res. 2001;9(8):470-7. 
16. Krakauer NY, Krakauer JC. A new body shape index predicts mortality hazard independently of body mass index. PLoS One. 2012;7(7):e39504.

17. Esteghamati A, Ashraf H, Esteghamati AR, et al. Optimal threshold of homeostasis model assessment for insulin resistance in an Iranian population: the implication of metabolic syndrome to detect insulin resistance. Diabetes Res Clin Pract. 2009;84(3):279-87.

18. Bravata DM, Wells CK, Concato J, et al. Two measures of insulin sensitivity provided similar information in a U.S. population. J Clin Epidemiol. 2004;57(11):1214-7.

19. Lee JM, Okumura MJ, Davis MM, Herman WH, Gurney JG. Prevalence and determinants of insulin resistance among U.S. adolescents: a population-based study. Diabetes Care. 2006;29(11):2427-32.

20. Geloneze B, Tambascia MA. Avaliação laboratorial e diagnóstico da resistência insulínica [Laboratorial evaluation and diagnosis of insulin resistance]. Arq Bras Endocrinol Metabol. 2006;50(2):208-15.

21. Geloneze B, Repetto EM, Geloneze SR, Tambascia MA, Ermetice MN. The threshold value for insulin resistance (HOMA-IR) in an admixtured population IR in the Brazilian Metabolic Syndrome Study. Diabetes Res Clin Pract. 2006;72(2):219-20.

22. Oliveira EP, Souza MLA, Lima MDA. Índice HOMA (homeostasis model assessment) na prática clínica: uma revisão [HOMA (homeostasis model assessment) index in clinical practice: a review]. J Bras Patol Med Lab. 2005:41(4):237-43.

23. Thompson WR, Gordon NF, Pescatello LS. ACSM's Guidelines for Exercise Testing and Prescription. $8^{\text {th }}$ edition. Philadelphia: Lippincott Williams \&Wilkins; 2010.

24. Ashwell M, Lejeune $S, M c P h e r s o n ~ K$. Ratio of waist circumference to height may be better indicator of need for weight management. BMJ. 1996;312(7027):377.

25. Nazare JA, Smith JD, Borel AL, et al. Ethnic influences on the relations between abdominal subcutaneous and visceral adiposity, liver fat, and cardiometabolic risk profile: the International Study of Prediction of Intra-Abdominal Adiposity and Its Relationship With Cardiometabolic Risk/Intra-Abdominal Adiposity. Am J Clin Nutr. 2012;96(4):714-26.

26. Ashwell M, Gunn P, Gibson S. Waist-to-height ratio is a better screening tool than waist circumference and BMI for adult cardiometabolic risk factors: systematic review and meta-analysis. Obes Rev. 2012;13(3):275-86.

27. Matos LN, Giorelli Gde V, Dias CB. Correlation of anthropometric indicators for identifying insulin sensitivity and resistance. Sao Paulo Med J. 2011;129(1):30-5.

28. Nadeem A, Naveed AK, Hussain MM, Raza SI. Cut-off values of anthropometric indices to determine insulin resistance in Pakistani adults. J Pak Med Assoc. 2013;63(10):1220-5.

29. Hadaegh F, Shafiee G, Azizi F. Anthropometric predictors of incident type 2 diabetes mellitus in Iranian women. Ann Saudi Med. 2009;29(3):194-200.
30. Wang F, Wu S, Song Y, et al. Waist circumference, body mass index and waist to hip ratio for prediction of the metabolic syndrome in Chinese. Nutr Metab Cardiovasc Dis. 2009;19(8):542-7.

31. Hadaegh F, Zabetian A, Harati H, Azizi F. Waist/height ratio as a better predictor of type 2 diabetes compared to body mass index in Tehranian adult men--a 3.6-year prospective study. Exp Clin Endocrinol Diabetes. 2006;114(06):310-5

32. Savva SC, Lamnisos D, Kafatos AG. Predicting cardiometabolic risk: waist-to-height ratio or BMI. A meta-analysis. Diabetes Metab Syndr Obes. 2013;6:403-19.

33. Després JP, Cartier A, Côté M, Arsenault BJ. The concept of cardiometabolic risk: Bridging the fields of diabetology and cardiology. Ann Med. 2008;40(7):514-23.

34. Primeau V, Coderre L, Karelis AD, et al. Characterizing the profile of obese patients who are metabolically healthy. Int J Obes (Lond). 2011;35(7):971-81.

35. Stefan N, Häring HU, Hu FB, Schulze MB. Metabolically healthy obesity: epidemiology, mechanisms, and clinical implications. Lancet Diabetes Endocrinol. 2013;1 (2):152-62.

36. Gaiță D, Moşteoru S. Metabolically healthy versus unhealthy obesity and risk for diabetes mellitus and cardiovascular diseases. Cardiovascular Endocrinology. 2017;6(1):23-6. Available from: http://journals. Iww.com/cardiovascularendocrinology/Abstract/2017/03000/ Metabolically_healthy_versus_unhealthy_obesity_and.6.aspx. Accessed in 2017 (Jul 13).

Sources of funding: Fundação de Amparo à Pesquisa do Estado de São Paulo (2011/07282-6)

Conflict of interest: None

Date of first submission: December 29, 2016

Last received: April 7, 2017

Accepted: April 28, 2017

\section{Address for correspondence:}

Flávio Rossi de Almeida

Departamento de Ciências do Movimento Humano, Universidade Federal de São Paulo (UNIFESP)

Rua Silva Jardim, 136

Santos — São Paulo (SP) — Brasil

CEP 11015-020

Cel. (+55 13) 98804-0831

Fax. (+55 13) 3040-2647

E-mail: almeida.f.rossi@gmail.com 